\title{
An Agonistic Antibody to EPHA2 Exhibits Antitumor Effects on Human Melanoma Cells
}

\author{
ATSUSHI SAKAMOTO ${ }^{1}$, KAZUNORI KATO ${ }^{2,3}$, TOSHIO HASEGAWA ${ }^{1}$ and SHIGAKU IKEDA ${ }^{1,2}$ \\ ${ }^{1}$ Department of Dermatology and Allergology, Juntendo University Graduate School of Medicine, Tokyo, Japan; \\ ${ }^{2}$ Atopy Research Center, Juntendo University Graduate School of Medicine, Tokyo, Japan; \\ ${ }^{3}$ Department of Biomedical Engineering, Toyo University, Saitama, Japan
}

\begin{abstract}
Background/Aim: EPH receptor A2 (EPHA2) is highly expressed in aggressive types of human cancer, and is expected to be an excellent target molecule for antibody treatments. In this study, we investigated the therapeutic potential of antibody to EPHA2 against melanoma in vitro. Materials and Methods: We generated three monoclonal antibodies (mAbs) to EPHA2 and examined cell-surface expression by flow cytometry. To investigate the ability to inhibit tumor cell migration therapy with mAbs to EPHA2, we performed a wound scratch assay and invasion assay. We investigated the therapeutic effects of immunotoxins consisting of toxin-conjugated EPHA2 mAbs. Results: All human melanoma cell lines studied expressed EPHA2. Like natural ligand ephrin-A1, one of EPHA2 mAbs, SHM16, inhibited metastatic behavior of cells, such as migration and invasion. In addition, drastic growth inhibition and cytotoxicity were found using immunotoxin-conjugated SHM16. Conclusion: These observations indicate a promising role for EPHA2 as a target in antibody treatments for melanoma, and demonstrate the potential therapeutic effects of an agonistic antibody to EPHA2.
\end{abstract}

Melanoma is the most aggressive type of skin cancer. While melanoma accounts for fewer than 5\% of all skin cancer cases, it is responsible for the large majority of deaths due to skin cancer. The type of treatment will depend not only on stage and location of the melanoma, but also on the patient's overall health. When melanoma has not grown deeper than the epidermis, it is usually treated by surgery

This article is freely accessible online.

Correspondence to: Kazunori Kato, Ph.D., Department of Biomedical Engineering, Toyo University, 2100 Kujirai, Kawagoe, Saitama 350-8585, Japan. Tel: +81 492391397, Fax: +81 492315026, e-mail: kzkatou@juntendo.ac.jp

Key Words: EPHA2, melanoma, monoclonal antibody, immunotoxin, invasion. (wide excision). When this is not possible, therapeutic options including injections of Bacille Calmette-Guerin (BCG) vaccine, interferon, or interleukin-2 (IL2) directly into the melanoma, radiation therapy, and chemotherapy (1, 2 ). The treatment of widespread melanoma has changed in recent years as newer forms of immunotherapy and molecularly-targeted drugs have been shown to be more effective than chemotherapy (3-6).

Receptor tyrosine kinases (RTKs) transmit signals that regulate cell proliferation and differentiation, promote cell migration and survival, and modulate cell metabolism. They play critical roles in a wide range of biological processes, including embryonic development, growth of an organism, angiogenesis, synaptic plasticity, and oncogenesis (7-9). EPH receptors, the largest subfamily of RTKs, are involved in many biological processes including angiogenesis, tissue-border formation, cell migration, and axon guidance $(10,11)$. EPH receptors and their ephrin ligands are important mediators of cell-to-cell communication that regulate cell attachment to the extracellular matrix, cell shape and cell motility. They have been studied extensively for their roles in the developmental process. In recent years, EPH receptors and ephrins have been found to be integral players in cancer formation and progression. EPH receptor A2 (EPHA2) and ephrin-A1 are especially known to be involved in the development and maintenance of many types of solid tumors (12-14).

EPHA2 was originally named epithelial cell kinase, due to its widespread expression in epithelial cells. Subsequent studies revealed that EPHA2 was overexpressed in human cancer, including melanoma, and that its overexpression was correlated with malignancy and poor prognosis. A large number of studies have demonstrated that EPHA2 overexpression and activation promote tumorigenesis, suggesting a potential role as an oncogene (15). EPHA2 activation by its ligand, ephrin-A1, regulates cell behavior in a manner more consistent with it being a tumor suppressor. Specifically, EPHA2 activation leads to induction of apoptosis, inhibition of cell proliferation, and suppression of cell migration $(16,17)$. Accordingly, EPHA2 has been found to be 
an integral player in cancer formation, and is expected to be a good target for antibody and small-agent therapy (18-20).

Recently, we established several monoclonal antibodies (mAbs) specific for human EPHA2. One of these mAbs, called SHM16, exhibited a unique function as an agonistic antibody to EPHA2. The first aim of the study was to determine if SHM16 could mimic the effects of the natural ligand ephrin-A1 in regulating melanoma cell migration and invasion. The second aim was to assess whether SHM16mediated targeting of toxin conjugates (immunotoxins) to EPHA2 would have antitumor effects against melanoma cells.

\section{Materials and Methods}

Cell lines. The melanoma cell lines A375, A2058, G361 were purchased from JCRB Cell Bank (Osaka, Japan), and SK-MEL28 was purchased from the American Type Culture Collection (Manassas, VA, USA). All cell lines, except fibroblasts and melanocytes (purchased from Lifeline Cell Technology, Frederick, MD, USA), were maintained in RPMI-1640 medium (Sigma-Aldrich, St. Louis, MO, USA) supplemented with $10 \%$ fetal bovine serum (FBS; Gibco by Life Technologies, Grand Island, NY, USA), 100 units $/ \mathrm{ml}$ penicillin $\mathrm{G}$ (Gibco), $100 \mu \mathrm{g} / \mathrm{ml}$ streptomycin (Gibco), and $25 \mathrm{mmol} / \mathrm{l}$ HEPES (Sigma-Aldrich) at $37^{\circ} \mathrm{C}$ in a humidified incubator with a $5 \%$ $\mathrm{CO}_{2}$ atmosphere. Fibroblasts were maintained in Dulbecco's modified Eagle's medium (DMEM) (Sigma-Aldrich) supplemented with $10 \%$ FBS, penicillin G and streptomycin, and HEPES. Melanocytes were maintained DermaLife Basal Medium (Lifeline Cell Technology) at $37^{\circ} \mathrm{C}$ in a humidified incubator with a $5 \% \mathrm{CO}_{2}$ atmosphere.

Establishment of mAbs to human EPHA2. SHM16, SHM17, and SHM20 mAbs against human EPHA2 were generated by immunizing $\mathrm{BALB} / \mathrm{c}$ mice with the human melanoma cell line A375. The immunized splenocytes were then fused to P3U1 mouse myeloma cells. The supernatants were harvested at 14 days post-fusion, and screened in a bioassay for activity against A375. This protocol for producing and screening targeted $\mathrm{mAbs}$ has been described in detail elsewhere $(21,22)$. After cloning by limiting dilution, we selected hybridoma cell colonies named SHM16, SHM17, and SHM20 (mouse $\mathrm{IgG} 1, \mathrm{~K})$. EPHA2 was identified as the antigen for all three antibodies by immunoprecipitation and biochemical analysis. To confirm the reactivity of SHM16, SHM17, and SHM20 with EPHA2, the A375 cell line was transfected with short interfering RNA (siRNA) targeting EPHA2 and incubated at $37^{\circ} \mathrm{C}$ for $72 \mathrm{~h}$. After this treatment, the reactivity of EPHA2 with A375 was examined by flow cytometry.

Reagents. Anti-EPHA2 mAbs were dissolved in sterilized phosphatebuffered saline (PBS) and kept as $1 \mathrm{mg} / \mathrm{ml}$ stock solutions. The mouse immunoglobulin G1 (IgG1) isotype control was purchased from BioLegend (San Diego, CA, USA). An ephrin-A1 fusion with the human $\operatorname{IgG}$ fragment crystallizable $(\mathrm{Fc})$ domain (ephrin-A1- $\mathrm{Fc}$ ) was purchased from R\&D systems (Minneapolis, MN, USA). Saporin-conjugated goat anti-mouse IgG (Mab-ZAP) was purchased from Advanced Targeting Systems (San Diego, CA, USA).

Identification of antigen recognized by SHM16. The molecules recognized by the mAb, SHM16 were identified by a two-step method as previously described in detail $(21,22)$. First, the cell-surface proteins of A375 cells were biotinylated and immunoprecipitated with the mAbs. The precipitated proteins were separated by sodium dodecyl sulfate polyacrylamide gel electrophoresis (SDS-PAGE) using 5-20\% gradient polyacrylamide gels (Bio-Rad, Hercules, CA, USA) and transferred onto nitrocellulose membranes (Millipore, MA, USA), and molecular weights of the immunoprecipitated proteins were then determined. In the second step, the immunocomplexes of A375 cells generated by the mAb separated by polyacrylamide gel was stained by using a Silver Stain kit (Wako Pure Chemical Industries, Ltd, Osaka, Japan) according to the company's recommendations. The specifically stained protein bands were extracted from the gel, digested by trypsin, and analyzed by oMALDI-Qq-TOF MS/MS QSTAR Pulsari (Applied Biosystems Japan Ltd, Tokyo, Japan).

Flow cytometric analysis. Cell-surface expression of EPHA2 was determined by flow cytometry. Approximately $1 \times 10^{6}$ cells were harvested from a monolayer culture, washed, and incubated with a saturating amount $(10 \mu \mathrm{g} / \mathrm{ml})$ of primary antibody in PBS ( $\mathrm{pH} 7.4)$ with $2 \%$ FBS (staining buffer) for $30 \mathrm{~min}$ on ice. The cells were then washed and stained with Alexa Fluor 488-conjugated goat anti-mouse IgG1 secondary antibody (diluted 1:100; Invitrogen) for $15 \mathrm{~min}$ on ice. Cells were then incubated with fluorescein-conjugated $\mathrm{mAb}$ for $30 \mathrm{~min}$ on ice. The cell suspension was washed three times with PBS, and then analyzed using a FACSCalibur flow cytometer (BD Immunocytometry Systems, Franklin Lakes, NJ, USA).

Cell proliferation assay. A375 cells were seeded and incubated at $37^{\circ} \mathrm{C}$ for 4 days with ephrin-A1-Fc or one of SHM16, SHM17, or SHM20 EPHA2 mAbs. After 4 days, AlamarBlue ${ }^{\circledR}$ reagent $(\mathrm{AbD}$ Serotec, Oxford, UK) was added to a final concentration of $10 \%$, and incubated with cells at $37^{\circ} \mathrm{C}$ for $3 \mathrm{~h}$. The fluorescence intensity was measured at a wavelength of $590 \mathrm{~nm}$ following excitation with a wavelength of $570 \mathrm{~nm}$.

Competitive inhibition assay of ephrin-A1-binding to EPHA2 by $m A b s$. Approximately $1 \times 10^{6}$ cells $(500 \mu$ l per tube) harvested from a monolayer culture were incubated with one of the anti-EPHA2 mAbs ( $1 \mu \mathrm{g} / \mathrm{ml} \mathrm{SHM16,} \mathrm{or} \mathrm{SHM17)} \mathrm{for} 1 \mathrm{~h}$ on ice, and then incubated subsequently with $3 \mu \mathrm{l}$ per tube ephrin-A1-Fc $(10 \mu \mathrm{g} / \mathrm{ml})$ for $1 \mathrm{~h}$ at room temperature. Cells were washed, and then stained with goat anti-human $\mathrm{IgG}$ (Fc-specific) conjugated with fluorescein 5-isothiocyanate (FITC) (Caltag Laboratories, Carlsbad, CA, USA) for $30 \mathrm{~min}$ on ice. The cell suspension was then washed three times with PBS, and analyzed using a FACSCalibur flow cytometer.

Scratch assay. Confluent A375 cells in a six-well plate were scratched with a pipette tip, and medium that also contained either $20 \mathrm{ng} / \mathrm{ml}$ of ephrin-A1-Fc, $10 \mu \mathrm{g} / \mathrm{ml}$ of SHM16 or SHM17 was added to induce migration. Cells were subsequently incubated at $37^{\circ} \mathrm{C}$ for $24 \mathrm{~h}$ before being photographed. The area of the scratch gap that remained open after this time was measured using Olympus DP2-BSW software (Tokyo, Japan).

Invasion assay. Biocoat Matrigel invasion chambers were purchased from BD Biosciences (Bedford, MA, USA). A375 cells $\left(2.5 \times 10^{4}\right.$ cells per well) were seeded into the upper chamber of trans-well inserts, and were maintained at $37^{\circ} \mathrm{C}$ throughout the experiment. Cells were allowed to migrate toward the lower chamber in media containing either $20 \mathrm{ng} / \mathrm{ml}$ of ephrin-A1-Fc, or $10 \mu \mathrm{g} / \mathrm{ml}$ of SHM16, for $24 \mathrm{~h}$. Cell migration was evaluated after crystal violet staining by counting cells in six randomly chosen fields. 
A

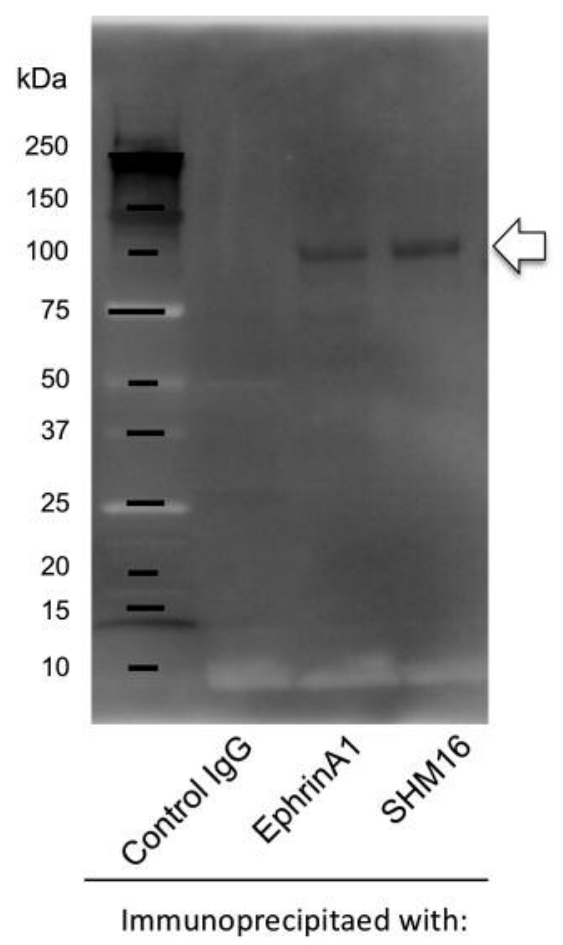

B

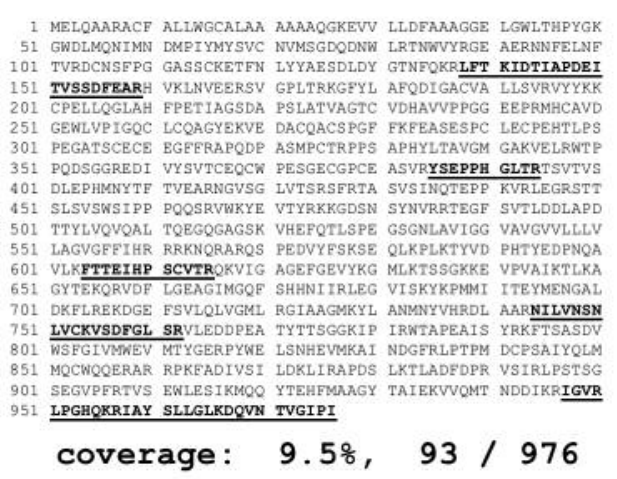

C

A375 stained with SHM16

EPHA2siRNA-A375 with SHM16

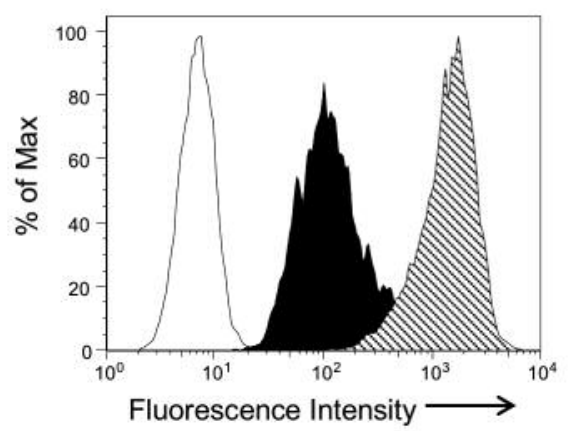

Figure 1. Characterization of the SHM16 antibody to EPH receptor A2 (EPHA2) by immunoprecipitation, mass spectrometric analysis and siRNAmediated knockdown of EPHA2 expression in A375 melanoma cells. A: The biochemical nature of the antigen recognized by SHM16 was examined by immunoprecipitation. The precipitates were first subjected to sodium dodecyl sulfate-polyacrylamide gel electrophoresis under reducing conditions, and then to fluorography. A band of $100 \mathrm{kDa}$ (indicated by an arrow) was precipitated by ephrin-A1 (lane 2) and the SHM16 antibody (lane 3). No band was precipitated with the IgG1 isotype control monoclonal antibody (lane 1). B: High-intensity spectra indicate the peptide, the sequence of which corresponded to the amino acid sequence of human EPHA2. Bold typeface indicates the sequence of the detected peptides by mass spectrometry. C: To knock-down EPHA2 protein levels, the A375 cell line was transfected with short interfering RNA (siRNA) targeting EPHA2 mRNA. After 3 days, the surface expression of EPHA2 on A375 cells was examined by flow cytometry.

Internalization of the SHM16, SHM17, and SHM2O EPHA2 mAbs. A375 cells $\left(1.0 \times 10^{4}\right.$ cells per well) were seeded into each well of four-well imaging chambers in media that included $2 \mu \mathrm{g} / \mathrm{ml}$ EPHA2 mAbs (SHM16, SHM17, or SHM20) and $2 \mu \mathrm{g} / \mathrm{ml}$ Alexa Fluor 488 goat anti-mouse $\mathrm{IgG} 1$ secondary antibody. After $24 \mathrm{~h}$ of incubation at $37^{\circ} \mathrm{C}$, photographs were taken using a confocal laser scanning microscope (FV10; OLYMPUS).

Targeted delivery of immunotoxin into melanoma cells. A375 cells were plated into a flat-bottom, 96 -well plate $(2,000$ cells per well) and incubated for 4 days at $37^{\circ} \mathrm{C}$ in a humidified incubator. This cell suspension with RPMI1640 medium included different concentrations of Mab-ZAP, along with either an anti-EPHA2 mAbs (SHM16, SHM17, or SHM20 at $2 \mu \mathrm{g} / \mathrm{ml}$ final concentration), or a control $\mathrm{IgG} 1 \mathrm{mAb}(2 \mu \mathrm{g} / \mathrm{ml}$ final concentration). After $24 \mathrm{~h}$, AlamarBlue reagent was added and plates were incubated at $37^{\circ} \mathrm{C}$ for a further $48 \mathrm{~h}$. The fluorescence intensity was then measured at an emission wavelength of $590 \mathrm{~nm}$.

\section{Results}

Specificity of SHM16 mAbs to human EPHA2. We established several mAbs specific for EPHA2 by immunizing BALB/c mice with the previously described A375 human melanoma cell line (23). In order to examine the specificity of the mAbs to EPHA2, we performed immunoprecipitation and siRNA transfection. The lysate of the surface biotinylated A375 was subjected to immunoprecipitation with SHM16-coupled or ephrin-A1-Fc-coupled Sepharose beads, and SDS-PAGE analysis was performed under reducing conditions. As shown 


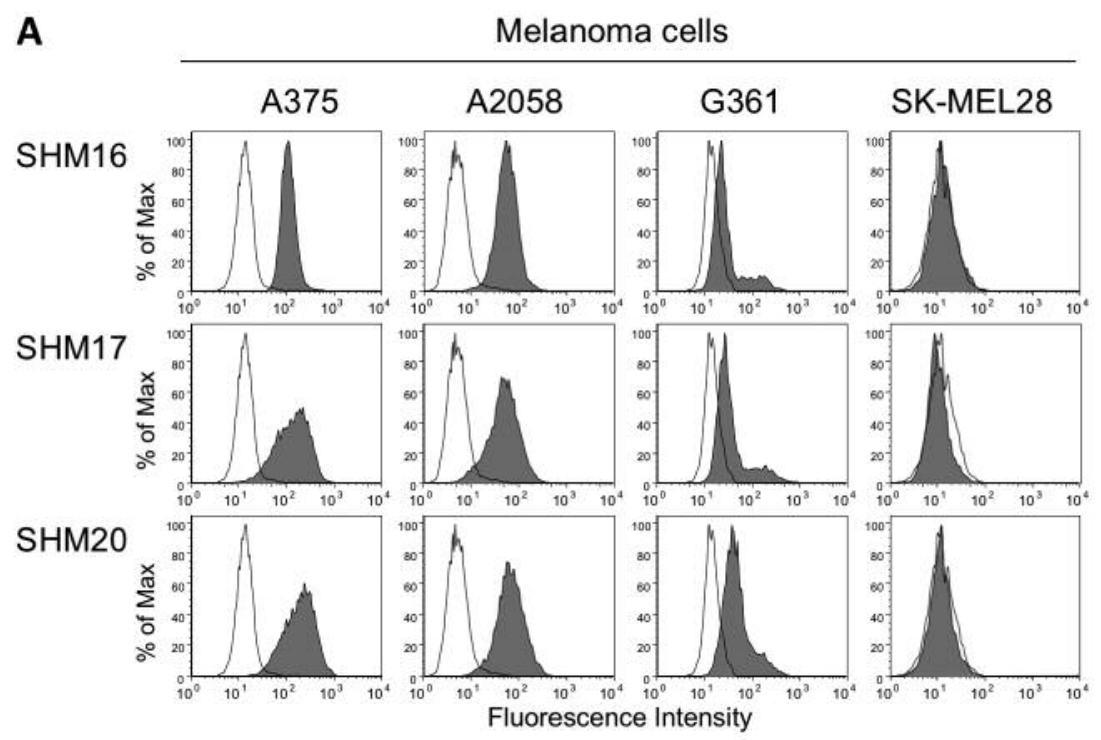

B Normal skin cells

\section{Normal lymphocytes}

\section{Melanocytes Fibroblasts}
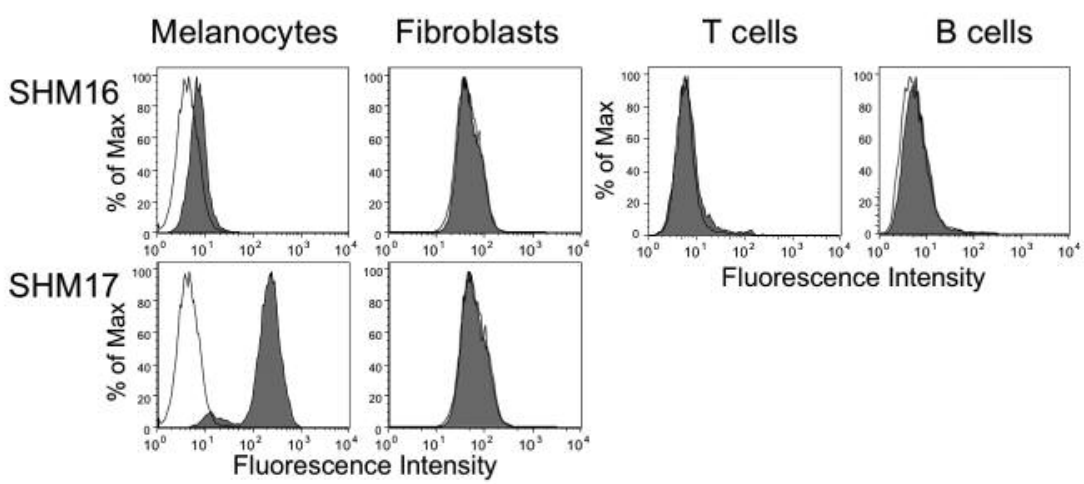

Fluorescence Intensity

Figure 2. Cell surface expression of EPH receptor A2 (EPHA2) on melanoma cells versus non-transformed cells. A: The reactivity of the EPHA2 antibodies to human melanoma cell lines was tested. Histograms show the results of flow cytometric analysis of (from left to right) A375, A2058, G361, and SK-MEL28 cell lines treated with (from top to bottom) SHM16, SHM17, and SHM20 antibodies. On each plot, the histogram from an isotype mouse IgG1 antibody control treatment is shown (clear histogram) along with the histogram from the respective antibody treatment (shaded histogram). B: The reactivity of the SHM16 (top) and SHM17 (bottom) antibodies with non-transformed human melanocytes (left) and fibroblasts (right) was examined by flow cytometry. Each plot shows the histogram from a control treatment with an isotype mouse IgG1 antibody (open histogram) and the histogram from an experimental treatment with the indicated antibody (shaded histogram). C: Expression of EPHA2 on human lymphocytes. Mononuclear cells were isolated from human peripheral blood and stained with fluorescence isothiocianate (FITC) conjugated antiCD3 or-CD19 antibody and SHM16 followed by phycoerythrin-conjugated anti-mouse IgG.

in Figure 1A, the antigens immunoprecipitated by SHM16 and ephrin-A1-Fc had similar apparent molecular masses of about $100 \mathrm{kDa}$. We then performed affinity purification andliquid chromatograph/tandem mass spectrometrywith the SHM16 antibody, and this analysis clearly identified human EPHA2 as the antigen (Figure 1B). To confirm the specificity of SHM16 for human EPHA2, we examined the reactivity of SHM16 to A375 cells that were transfected with EPHA2-specific siRNA or a control siRNA (scrambled). Transfection with EPHA2
siRNA resulted in a significant decrease in the reactivity of A375 with not only SHM16 mAb (Figure 1C), but also with SHM17 and SHM20 mAbs (data not shown). We, therefore, conclude that the antigen recognized by SHM16, SHM17, and SHM20 is EPHA2.

Cell-surface expression of EPHA2 on human melanoma cells. Flow cytometry was used to examine the expression of EPHA2 on the surface of the human melanoma cell lines 
A

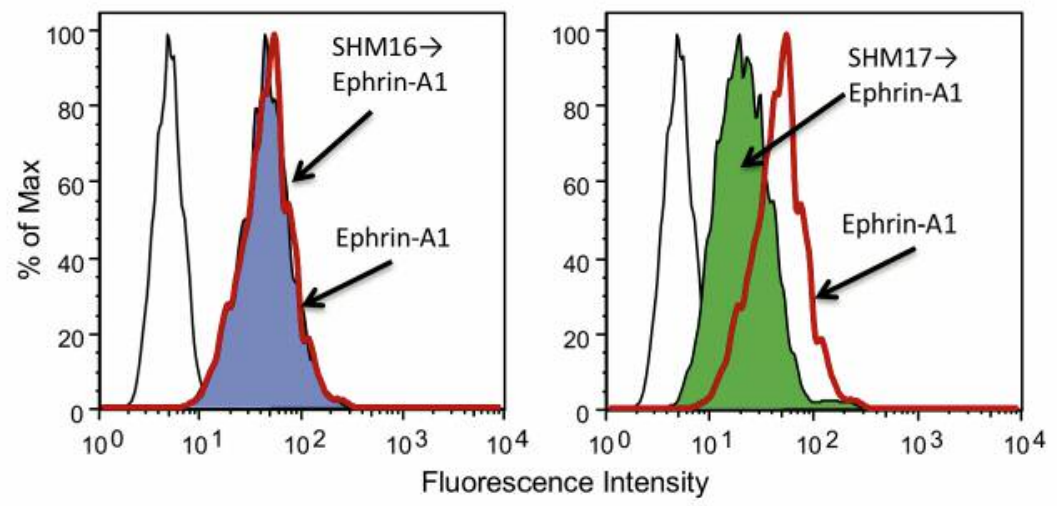

Figure 3. Assays for competitive inhibition of ephrin-A1 binding to EPH receptor A2 (EPHA2) by SHM16 and SHM17. Approximately $1 \times 10^{6}$ A375 cells $(500 \mu \mathrm{l} \mathrm{per} \mathrm{tube)} \mathrm{harvested} \mathrm{from} \mathrm{a} \mathrm{monolayer} \mathrm{culture} \mathrm{were} \mathrm{incubated} \mathrm{with} 3 \mu \mathrm{l}$ anti-EPHA2 antibody per tube (SHM16 or SHM17, $1 \mu \mathrm{g} / \mathrm{ml})$ for $1 \mathrm{~h}$ on ice, and subsequently incubated with $3 \mu \mathrm{l} \mathrm{ephrin-A1-Fc} \mathrm{per} \mathrm{tube}(10 \mu \mathrm{g} / \mathrm{ml})$ for $1 \mathrm{~h}$ at room temperature. Cells were then washed and stained with goat anti-human IgG (Fc specific), conjugated with fluorescence isothiocianate (FITC) for 30 min on ice.

A375, A2058, G361, and SK-MEL28, as well as on normal skin melanocytes and fibroblasts. Of the four cell lines examined, EPHA2 was expressed on A375, and A2058 and faintly expressed on G361 cells (Figure 2A). Conversely, human dermal fibroblasts were found to be negative for EPHA2 using SHM16 and SHM17 (Figure 2B). The expression of EPHA2 was found in normal melanocytes using SHM17, however the reactivity of SHM16 with melanocytes was far weaker. In addition, human T- and Blymphocytes were also negative for EPHA2 (Figure 2C). These data indicated that EPHA2 would be a suitable target for antibody treatment of melanoma using the SHM16 mAb.

SHM17, but not SHM16, interferes with binding of ephrin-A1 to EPHA2. In order to determine the difference between the epitopes recognized by SHM16 and SHM17, we next tested their ability to competitively inhibit ephrin-A1 binding to EPHA2 on the surface of A375 cells, using flow cytometry to detect binding. We found that SHM17 significantly interfered with binding of ephrin-A1 to EPHA2 (Figure 3). In contrast, SHM16 did not affect ephrin-A1 binding to EPHA2 on the surface of A375 cells. These data suggested that SHM17 would act as an antagonistic mAb, while SHM16 recognizes an alternative epitope of EPHA2 (Figure 3).

Inhibition of tumor cell migration by anti-EPHA2. It has been reported that EPH receptor ligands influence cell migration and invasion $(24,25)$. To investigate whether EPHA2 mAbs have the ability to inhibit tumor cell migration, we performed a wound scratch assay and a Matrigel invasion assay using A375 melanoma cells. Similarly to the natural ligand ephrin-A1, SHM16 suppressed migration and invasion by A375 human melanoma cells (Figures 4). However, the antagonistic antibody SHM17 was unable to inhibit tumor cell migration and invasion (Figure 4A). Overall, SHM16 stimulated signaling by EPHA2 that reduced A375 cell motility, indicating that it may be an agonistic EPHA2 mAb.

Therapeutic effect of a combination of immunotoxin and anti-EPHA2. We finally investigated the therapeutic effects of immunotoxins consisting of combinations of EPHA2 mAbs with a saporin-conjugated secondary antibody. Firstly, the internalization of SHM16 and SHM17 by A375 melanoma cells was analyzed using confocal laser scanning microscopy. As shown in Figure 5A, fluorophore- labeled SHM16 was clearly internalized by A375 cells, whereas SHM17 remained on the cell surface. Next, we examined the effect of anti-EPHA2 immunotoxins on cell growth and survival. Growth inhibition and cytotoxicity were found following targeted delivery of saporin by SHM16 and SHM20 (Figure 5B). As shown in Figure 5C, the therapeutic potential of antibody-mediated cytotoxin delivery by SHM16 and SHM20 was investigated using A375, A2058, G361, and SK-MEL28 human melanoma cell lines. Drastic growth inhibition and cytotoxicity were observed following targeted delivery of saporin by SHM16, and occurred in a dosedependent manner.

\section{Discussion}

EPHA2 is a member of the EPH family of RTKs and is highly expressed in aggressive human cancer, including melanoma (26). By immunization with the A375 human melanoma cell line, we have established several mouse mAbs specific for human EPHA2. In this study, we examined whether EPHA2 
A
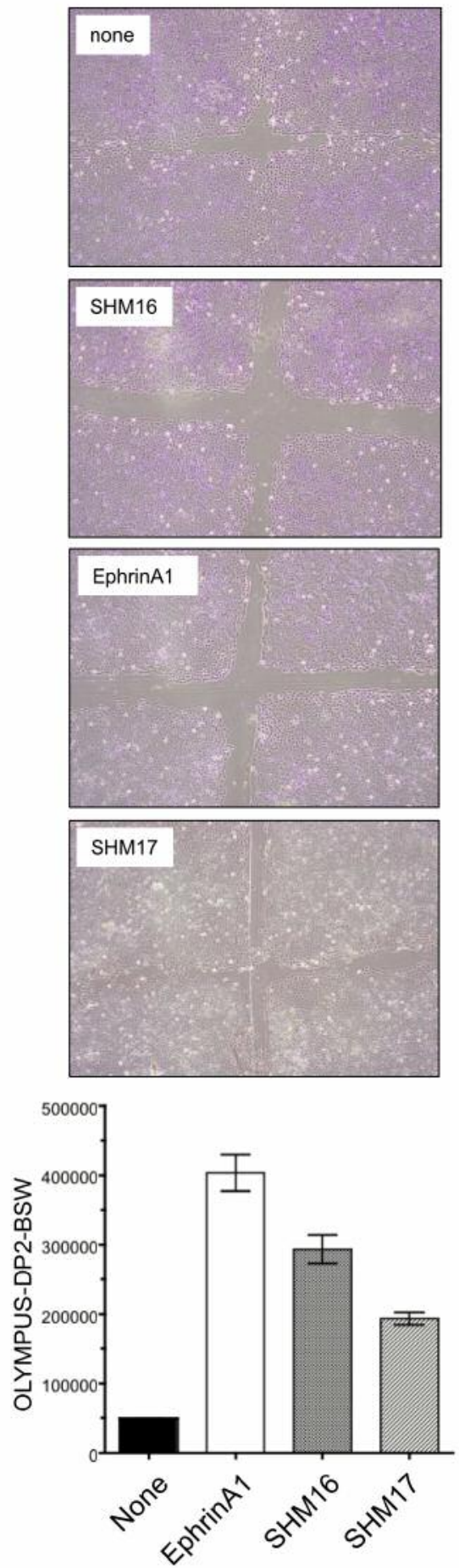

B
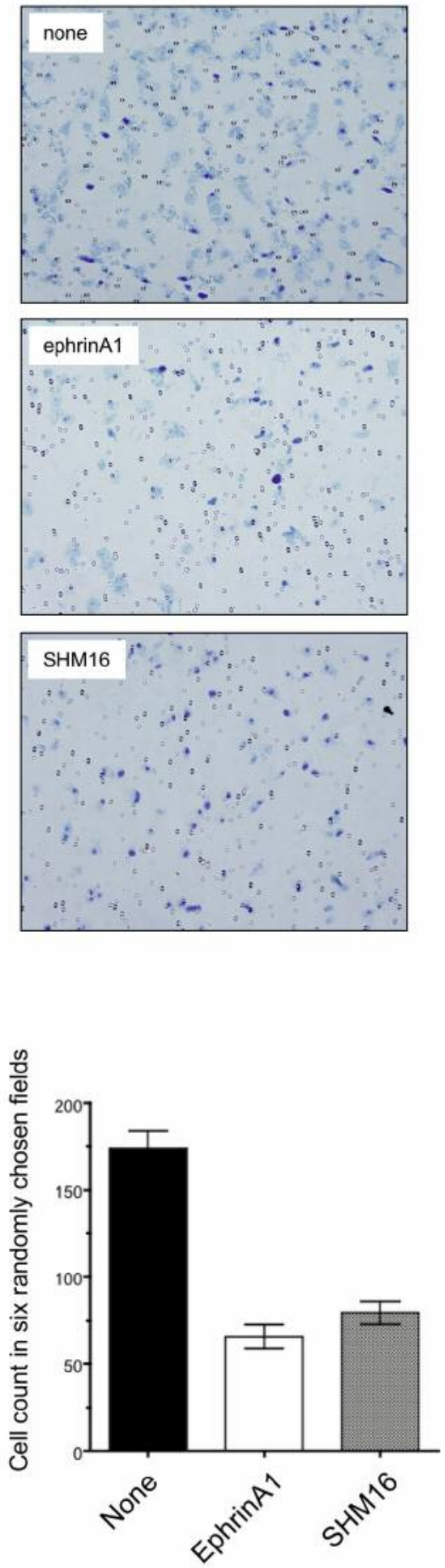

Figure 4. Impact of SHM16 and SHM17 treatment on migration by A375 melanoma cells in vitro. A: Scratch assay. A confluent A375 cell culture was scratched with a pipette tip, and medium was added to induce migration of cells in the wound. The medium was either supplemented with ephrin-Al-Fc (20 $\mathrm{ng} / \mathrm{ml})$, SHM16 $(10 \mu \mathrm{g} / \mathrm{ml})$, SHM17 $(10 \mu \mathrm{g} / \mathrm{ml})$, or not at all (none). After a 24-h incubation, photographs were taken of each condition (left). The area of the open gap that remained was measured using the Olympus DP2-BSW software and is indicated on the bar graph (right) for each condition. *Significantly different at $p<0.01$ compared to the non-supplemented condition. B: Invasion assay. A375 cells were seeded into the upper chambers of trans-well inserts. Cells were allowed to migrate for 24 h toward the lower chamber in medium containing ephrin-Al-Fc $(20 \mathrm{ng} / \mathrm{ml})$ or SHM16 $(10 \mu \mathrm{g} / \mathrm{ml})$, or without anything added (none). Cell migration was evaluated after crystal violet staining by counting cells in six randomly chosen fields. *Significantly different at $p<0.01$ compared to control. 

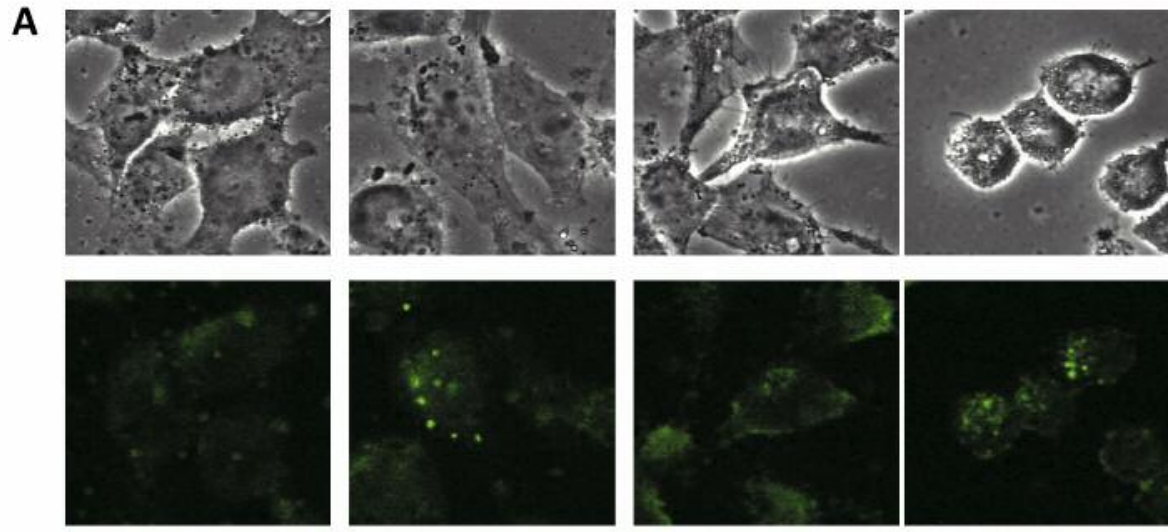

None

SHM16

SHM17

SHM20

B

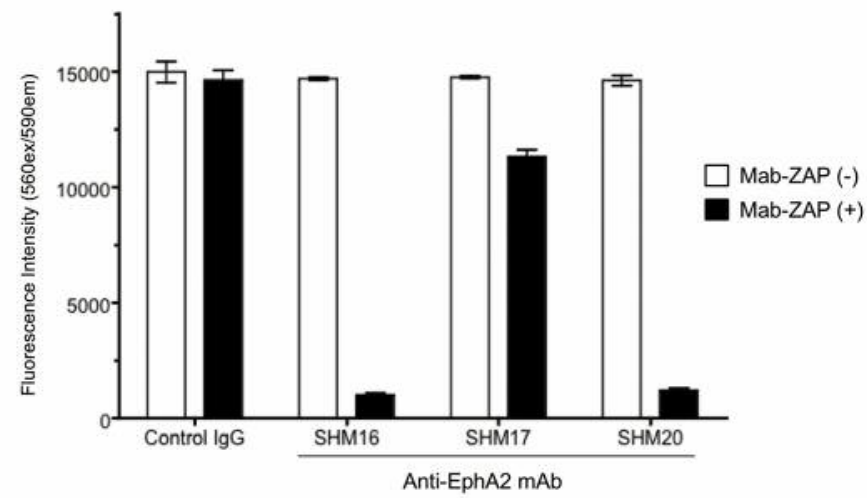

C
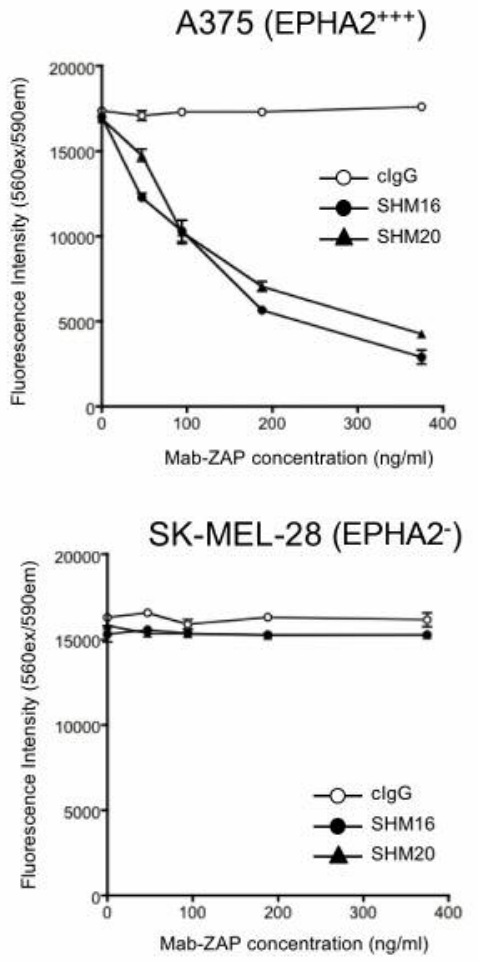
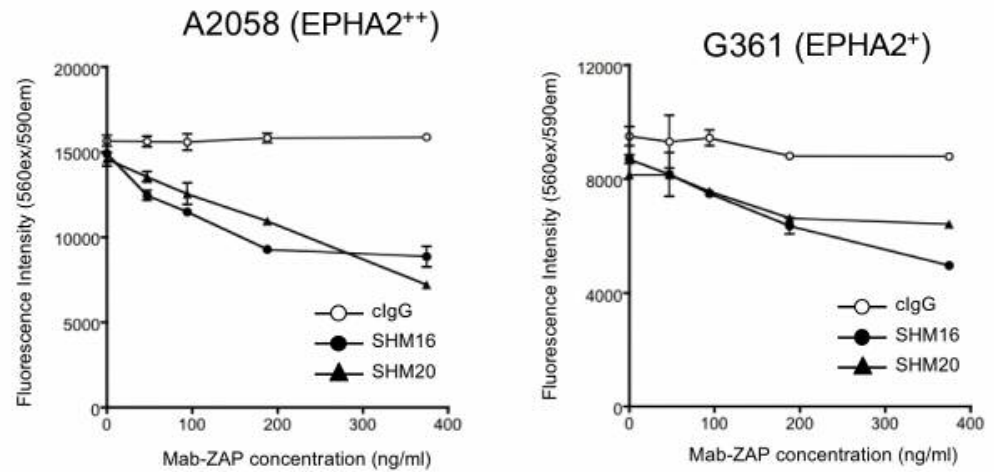

Figure 5. Therapeutic effects of antibodies to EPH receptor A2 (EPHA2) when combined with an immunotoxin. A: Internalization of EPHA2 antibodies SHM16, SHM17, and SHM2O by A375 cells. Cells were seeded into each well of a four-well tissue plate in medium with one of the EPHA2 antibodies $(2 \mu \mathrm{g} / \mathrm{ml})$, and Alexa Fluor 488-conjugated goat anti-mouse IgG1 secondary antibody (2 $\mu \mathrm{g} / \mathrm{ml}$ ). A control well (None) had no primary antibody added but contained Alexa Fluor 488conjugated goat anti-mouse IgG1 secondary antibody $(2 \mu \mathrm{g} / \mathrm{ml})$. After $24 \mathrm{~h}$ of incubation, photographs were taken under confocal laser scanning microscopy. Phase-contrast images (top) and fluorescent images (bottom) are shown for each condition. B: The cytotoxic effects of treatment with anti-EPHA2 in combination with an immunotoxin. A375 cells were plated into a flat-bottom, 96-well plate $(2,000$ cells per well) and incubated for 4 days at $37^{\circ} \mathrm{C}$. Wells contained $2 \mu \mathrm{g} / \mathrm{ml}$ of SHM16, SHM17, SHM20, or a control IgG1 monoclonal antibody, with or without saporin-conjugated goat anti-mouse IgG (Mab-ZAP, $750 \mathrm{ng} / \mathrm{ml})$. After $24 \mathrm{~h}$, AlamarBlue reagent was added to the medium, and cells were incubated at $37^{\circ} \mathrm{C}$ for $48 \mathrm{~h}$. The fluorescence intensity was measured at $590 \mathrm{~nm}$ following excitation at $570 \mathrm{~nm}$. *Significantly different at $p<0.01$ compared to the control. $C$ : The therapeutic effects of SHM16 and SHM20 against the human melanoma cell lines A375, A2058, G361, and SK-MEL28 were investigated using an antibody-mediated cytotoxicity assay. 
could be an integral player in cancer formation, and whether it could be a viable target for antibody therapy.

EPHA2 pathways are now viewed as intricate signaling networks containing modules of multi-protein complexes that assemble in various intracellular compartments to process, integrate, and transmit information that will ultimately specify a particular biological response (27). The interaction of natural ligands such as ephrin-A1 with EPHA2 receptor induces phosphorylation of a tyrosine motif in the cytoplasmic domain of EPHA2. Downstream of EPHA2 activation, an essential effector cascade required for most of the EPH receptor functions is the mitogen-activated protein kinase (MAPK) cascade. The MAPK cascade is comprised of the MAP kinase kinase (RAF), MAPK kinase (MEK), and extracellular signal-regulated kinase (ERK) kinases. The MAPK pathway includes several key signaling components, and phosphorylation events, that play roles in tumorigenesis. These activated kinases transmit extracellular signals that regulate cell growth, differentiation, proliferation, and migration, as well as apoptosis. Alteration of the RAS (oncogene of rat sarcoma)-RAF-MEK-ERK-MAPK (RASMAPK) pathway has been reported in human cancer as a result of abnormal activation of RTKs, or gain-of-function mutations mainly in the RAS or RAF genes (28-30).

Recently, targeted therapies have emerged as promising modality for cancer treatment. Various cancer-associated antigens have been targeted by immunotherapies such as cancer vaccine peptides, small interfering RNAs, and recombinant antibodies $(18-20,31)$. It is possible that the abundant expression of EPHA2 on the surface of malignant cells would make it a suitable target molecule for various cancer therapies. We found that human melanoma cell lines expressed EPHA2 on their surface, whereas normal dermal fibroblasts did not. We also examined the expression of EPHA2 by normal hematopoietic cells including lymphocytes, neutrophil, erythrocytes, and platelets (as shown in Figure 2C). Our data indicate that normal cells were generally not affected due to lack of EPHA2 expression. Interestingly, significant reactivity of our SHM17 anti-EPHA2 mAb with normal cultured melanocytes was observed, however, only faint reactivity of SHM16 with melanocytes was observed. In order to identify the epitope recognized by these anti-EPHA 2 mAbs, we performed a competitive inhibition assay with these antibodies competing against ephrin-A1 to bind to EPHA2. As shown in Figure 3, binding of ephrin-A1 to EPHA2 on melanoma cells was competitively interfered with by treatment with SHM17, but not SHM16. In addition, we found that SHM16, but not SHM17, was internalized by A375 human melanoma cells. Considered together, these results strongly suggest that the epitopes recognized by SHM16 and SHM17 are distinct.

The functions of the EPHA2/ephrin-A1 system in tumorigenesis and angiogenesis make it a very attractive therapeutic target. Several studies showed that artificial ligands to EPHA2 inhibited tumor invasion and metastasis. Petty et al. showed that a small-molecule agonist of the EPHA2 RTK inhibited tumor cell migration in prostate cancer (20). They found that the agonistic small molecule inhibited AKT/ERK kinase activities. Synthetic peptides designed to selectively bind EPHA2 were reported to induce tyrosine phosphorylation of EPHA2 in cultured cells (32). Based on these findings, similarly to the natural ligand ephrin-A1, SHM16 also appears to be able to inhibit melanoma metastatic potential by affecting cell migration and invasion.

A number of these therapeutic approaches, including antibody-drug conjugates, immunotoxins, and targeted nucleic acid delivery, require antibodies that not only bind a receptor but also undergo internalization into the cell $(33,34)$. We previously reported the ability to generate cancer cellspecific internalized antibodies directly from antibody libraries selected for internalization into cancer cell lines (21, 35). Using an Adv-FZ33 screening system, we were able to selectively obtain different mAbs that had high affinity, and recognized antigens of high structure. As shown in Figure 5, specific and efficient immunotoxin delivery into melanoma cells was achieved following treatment with the SHM16 EPHA2 mAb and a saporin-conjugated secondary antibody. Drastic dose-dependent growth inhibition and cytotoxicity were observed using this approach, indicating that SHM16 immunotoxins targeting EPHA2 exhibit antitumor effects. Overall, we have succeeded in generating an agonistic antibody to EPHA2 that might be useful as a targeted therapy against melanoma. Similar results have been shown in colorectal and breast cancer (data not shown). Considering the differences in the cell lines, further studies are needed to clarify the relative contributions of ephrin-A1-EPHA2 signaling activities to tumor growth.

\section{Disclosure Statement}

The Authors have no conflicts of interest in regard to this study.

\section{Acknowledgements}

The Authors wish to thank Sachie Hirai and Professor Hirofumi Hamada (Sapporo Medical University) for helpful discussion. The Authors also thank Taro Kojima and Ritsuko Harigai (Toyo University) for their helpful technical assistant. This work was supported in part by Grant-in-Aid for Scientific Research (B) from the Ministry of Education, Culture, Sports, Science and Technology of Japan (K. Kato).

\section{References}

1 Bergmann L: Malignant melanoma-prognosis and actual treatment strategies with chemotherapy and biological response modifiers. Eur J Cancer Clin Oncol 25: 31-36, 1989.

2 Zikich D, Schachter J and Besser MJ: Immunotherapy for the treatment of advanced melanoma: the next steps. Am J Clin Dermatol 14: 261-272, 2013. 
3 Kirkwood JM, Tarhini AA, Panelli MC, Moschos SJ, Zarour HM, Butterfield LH and Gogas HJ: Next-generation of immunotherapy for melanoma. J Clin Oncol 26: 3445-3455, 2008.

4 Hodi FS, O'Day SJ, McDermott DF, Weber RW, Sosman JA, Haanen JB, Gonzalez R, Robert C, Schadendorf D, Hassel JC, Akerley W, van den Eertwegh AJ, Lutzky J, Lorigan P, Vaubel JM, Linette GP, Hogg D, Ottensmeier CH, Lebbé C, Peschel C, Quirt I, Clark JI, Wolchok JD, Weber JS, Tian J, Yellin MJ, Nichol GM, Hoos A and Urba WJ: Improved survival with ipilimumab in patients with metastatic melanoma. N Engl J Med 363: 711-723, 2010.

5 Robert C, Ribas A, Wolchok JD, Hodi FS, Hamid O, Kefford R, Weber JS, Joshua AM, Hwu WJ, Gangadhar TC, Patnaik A, Dronca R, Zarour H, Joseph RW, Boasberg P, Chmielowski B, Mateus C, Postow MA, Gergich K, Elassaiss-Schaap J and Li XN, Iannone R, Ebbinghaus SW, Kang SP and Daud A: Antiprogrammed-death-receptor-1 treatment with pembrolizumab in ipilimumab-refractory advanced melanoma: a randomised dosecomparison cohort of a phase 1 trial. The Lancet 384: 11091117,2014

6 Meier F, Busch S, Lasithiotakis K, Kulms D, Garbe C, Maczey E, Herlyn M and Schittek B: Combined targeting of MAPK and AKT signaling pathways is a promising strategy for melanoma treatment. Br J Dermatol 156: 1204-1213, 2007.

7 Sinnberg T, Lasithiotakis K, Niessner H, Schittek B, Flaherty KT, Kulms D, Maczey E, Campos M, Gogel J, Garbe C and Meier F: Inhibition of PI3K-AKT-mTOR signaling sensitizes melanoma cells to cisplatin and temozolomide. J Invest Dermatol 129: 1500-1515, 2009.

8 Jiang X, Zhou J, Yuen NK, Corless CL, Heinrich MC, Fletcher JA, Demetri GD, Widlund HR, Fisher DE and Hodi FS: Imatinib targeting of KIT-mutant oncoprotein in melanoma. Clin Cancer Res 14: 7726-7732, 2008.

9 Lasithiotakis KG, Sinnberg TW, Schittek B, Flaherty KT, Kulms D, Maczey E, Garbe C and Meier FE: Combined inhibition of MAPK and mTOR signaling inhibits growth, induces cell death, and abrogates invasive growth of melanoma cells. J Invest Dermatol 128: 2013-2023, 2008.

10 Zhang $\mathrm{J}$ and Hughes S: Role of the ephrin and EPH receptor tyrosine kinase families in angiogenesis and development of the cardiovascular system. J Pathol 208: 453-461, 2006.

11 Kuijper S, Turner CJ and Adams RH: Regulation of angiogenesis by EPH-ephrin interactions. Trends Cardiovasc Med 17: 145-151, 2007.

12 Herath NI and Boyd AW: The role of EPH receptors and ephrin ligands in colorectal cancer. Int J Cancer 126: 2003-2011, 2010.

13 Pasquale EB: EPH receptors and ephrins in cancer: bidirectional signaling and beyond. Nat Rev Cancer 10: 165-180, 2010.

14. Xi HQ, Wu XS, Wei B and Chen L: EPH receptors and ephrins as targets for cancer therapy. J Cell Mol Med 16: 2894-2909, 2012.

15 Shen W, Xi H, Zhang K, Cui J, Li J, Wang N, Wei B and Chen L: Prognostic role of EPHA2 in various human carcinomas: a meta-analysis of 23 related studies. Growth Fac 32: 247-253, 2014

16 Taddei ML, Parri M, Anqelucci A, Onnis B, Bianchini F, Giannoni E, Raugei G, Calorini L, Rucci N, Teti A, Bologna M and Chiarugi P: Kinase-dependent and independent roles of EPHA2 in the regulation of prostate cancer invasion and metastasis. Am J Path 174: 1492-1503, 2009.
17 Wykosky J and Debinski W: The EPHA2 receptor and ephrin A1 ligand in solid tumors: function and therapeutic targeting. Mol Cancer Res 6: 1795-1806, 2008.

18 Wykosky J, Gibo DM and Debinski W: A novel, potent, and specific ephrinA1-based cytotoxin against EPHA2 receptor expressing tumor cells. Mol Cancer Ther 6: 3208-3218, 2007.

19 Goldgur Y, Susi P, Karelehto E, Sanmark H, Lamminmäki U, Oricchio E, Wendel HG, Nikolov DB and Himanen JP: Generation and characterization of a single-chain anti-EPHA2 antibody. Growth Factors 32: 214-222, 2014

20 Petty A, Myshkin E, Qin H, Guo H, Miao H, Tochtrop GP, Hsieh JT, Page P, Liu L, Lindner DJ, Acharya C, MacKerell AD Jr., Ficker E, Song J and Wang B: A small molecule agonist of EPHA2 receptor tyrosine kinase inhibits tumor cell migration in vitro and prostate cancer metastasis in vivo. PLoS One 7: e42120, 2012.

21 Suzuki K, Nakamura K, Kato K, Hamada H and Tsukamoto T: Eploration of target molecules for prostate cancer gene therapy. Prostate 67: 1163-1173, 2007.

22 Tanaka T, Huang J, Hirai S, Kuroki M, Kuroki M, Watanabe N, Tomihara K, Kato K and Hamada H: Carcinoembryonic antigentargeted selective gene therapy of gastric cancer through FZ33 fibermodified adenovirus vectors. Clin Cancer Res 12: 3803-3813, 2006.

23 Takenouchi M, Hirai S, Sakuragi N, Yagita H, Hamada H, Kato $\mathrm{K}$ : Epigenetic modulation enhances the therapeutic effect of antiIL-13Ra2 antibody in human mesothelioma xenografts. Clin Cancer Res 17: 2819-2829, 2011.

24 Liu Y, Yu C, Qiu Y, Huang D, Zhou X, Zhang X and Tian Y: Down-regulation of EPHA2 expression suppresses the growth and metastasis in squamous-cell carcinoma of the head and neck in vitro and in vivo. J Cancer Res Clin Oncol 138: 195-202, 2012.

25 Nishimura M, Jung EJ, Shah MY, Lu C, Spizzo R, Shimizu M, Han HD, Ivan C, Rossi S, Zhang X, Nicoloso MS, Wu SY, Almeida MI, Bottsford-Miller J and Pecot CV, Zand B, Matsuo K, Shahzad MM, Jennings NB, Rodriguez-Aguayo C, LopezBerestein G, Sood AK and Calin GA: Therapeutic synergy between microRNA and siRNA in ovarian cancer treatment. Cancer Discov 3: 1302-1315, 2013.

26 Udayakumar D, Zhang G, Ji Z, Njauw CN, Mroz P and Tsao H: EPHA2 is a critical oncogene in melanoma. Oncogene 30: 49214929, 2011.

27 Beauchamp A and Debinsky W: EPHS and ephrins in cancer: ephrin-A1 signaling. Semin Cell Dev Biol 23: 109-115, 2012.

28 Sosman JA, Kim KB, Schuchter L, Gonzalez R, Pavlick AC, Weber JS, McArthur GA, Hutson TE, Moschos SJ, Flaherty KT, Hersey P, Kefford R, Lawrence D, Puzanov I, Lewis KD, Amaravadi RK, Chmielowski B, Lawrence HJ, Shyr Y, Ye F, Li J, Nolop KB, Lee RJ, Joe AK and Ribas A: Survival in BRAF V600-mutant advanced melanoma treated with Vemurafenib. N Engl J Med 366: 707-714, 2012.

29 Collisson EA, De A, Suzuki H, Gambhir SS and Kolodney MS: Treatment of metastatic melanoma with an orally available inhibitor of the RAS-RAF-MAPK cascade. Cancer Res 63: 5669-5673, 2003.

30 Flaherty KT, Infante JR, Daud A, Gonzalez R, Kefford RF, Sosman J, Hamid O, Schuchter L, Cebon J, Ibrahim N, Kudchadkar R, Burris HA 3rd, Falchook G, Algazi A, Lewis K, Long GV, Puzanov I, Lebowitz P, Singh A, Little S, Sun P, Allred A, Ouellet D, Kim KB, Patel K and Weber J: Combined BRAF and MEK inhibition in melanoma with BRAF V600 mutations. N Engl J Med 367: 1694-1703, 2012. 
31 Biao-xue R and Xi-guang C, Shuan-ying Y, Wei L and Zongjuan M: EPHA2-dependent molecular targeting therapy for malignant tumors. Curr Cancer Drug Targets 11: 1082-1097, 2011.

32 Borthakur S, Lee H, Kim S, Wang BC and Buck M: Binding and function of phosphotyrosines of the ephrin A2 (EPHA2) receptor using synthetic sterile a motif (SAM) domains. J Biol Chem 289: 19694-19703, 2014.

33 Jackson D, Gooya J, Mao S, Kinneer K, Xu L, Camara M, Fazenbaker C, Fleming R, Swamynathan S, Meyer D, Senter PD, Gao C, Wu H, Kinch M, Coats S, Kiener PA and Tice DA: A human antibody-drug conjugate targeting EPHA2 inhibits tumor growth in vivo. Cancer Res 68: 9367-9374, 2008 .
34 Lee JW, Han HD, Shahzad MM, Kim SW, Mangala LS, Nick AM, Lu C, Langley RR, Schmandt R, Kim HS, Mao S, Gooya J, Fazenbaker C, Jackson D, Tice DA, Landen CN, Coleman RL and Sood AK: EPHA2 immunoconjugates as molecularly targeted chemotherapy for ovarian carcinoma. J Natl Cancer Inst 101: 1193-1205, 2009.

35 Takahashi S, Kato K, Nakamura K, Nakano R, Kubota K and Hamada H: Neural cell adhesion molecule 2 as a target molecule for prostate and breast cancer gene therapy. Cancer Sci 102: 808814, 2011.

Received January 9, 2018

Revised May 12, 2018

Accepted May 15, 2018 